\title{
Low-frequency underwater sound generation by impacting transient cylindrical water jets
}

\author{
Ali R. Kolaini \\ National Center for Physical Acoustics, The University of Mississippi, Coliseum Drive, \\ University, Mississippi 38677 \\ Ronald A. Roy and Lawrence A. Crum \\ Applied Physics Laboratory, University of Washington, 1013 NE 40th Street, Seattle, Washington 98105 \\ Yi Mao \\ National Center for Physical Acoustics, The University of Mississippi, Coliseum Drive, \\ University, Mississippi 38677
}

(Received 10 August 1992; revised 23 November 1992; accepted 12 July 1993)

The impact of a jet of water onto a still-water surface results in the entrainment of large amounts of air and the eventual formation of a bubble plume. Results from an experimental study of the noise produced by this process is presented. Preliminary results of this study were reported previously by Kolaini et al. [J. Acoust. Soc. Am. 89, 2452-2455 (1991)]. The densely populated bubble plumes were generated by dropping a fixed volume of water, held in a cylindrical container, onto a still-water surface. High-speed video images reveal the formation of a cylindrical bubble plume with a very high void fraction which grows in size until all the water is injected into the tank. As the leading end of the plume advances, a section of the plume separates near the crater region formed by the jet. After detachment, the separated plume, which is roughly spherical in shape, undergoes volume pulsations, and radiates relatively large-amplitude, low-frequency sound. The nature of the acoustic emissions from bubble plumes depends on the height of the water in the container, the container's radius, and the velocity of the impacting jet. The natural frequency of oscillation of an individual bubble plume is inversely proportional to the radius of the plume and ranges from a few tens of $\mathrm{Hz}$ to over $100 \mathrm{~Hz}$ depending upon the void fraction of air contained within the plume. Results obtained with salt water as well as with rough jets are also discussed. The high-speed video observations reveal that immediately following the bubble plume detachment, there is evidence of an axial jet directed downward into the bubble plume and an opposing jet directed upward into the crater formed by the impact. This jet appears to be the physical mechanism that drives the cloud into oscillation. Measurements indicate that the acoustic intensity radiated from bubble plumes correlate with the total potential energy of the water jet.

PACS numbers: $43.30 . \mathrm{Nb}$

\section{INTRODUCTION}

Recently, considerable attention has been devoted to the understanding of ambient sound in the ocean. The earliest measurements of ambient-sound spectra levels in the ocean were reported by Knudsen et al. (1948). They showed that the sound spectral level depends on wind speed and decreases with increasing frequency at the rate of approximately $5 \mathrm{~dB} /$ oct. Later, Wenz (1962) reviewed the data from Knudsen et al. and concluded that gas bubbles generated by breaking waves are a major contributor to underwater noise. Recently, there have been two conferences devoted to the understanding of the source mechanisms for ambient noise production at the sea surface (Kerman, 1988, 1993) where many of the mechanism for underwater ambient noise were discussed in some detail. Some of these bubble-related mechanisms include linear and nonlinear bubble oscillations (Prosperetti, 1988; Crowther, 1988; Longuet-Higgins, 1989, 1990a,b), splash or rain noise (Scrimger, 1985; Scrimger et al., 1989; Pumphery et al., 1989; Pumphery and Crum, 1990; Pros- peretti et al., 1989; Ogüz and Prosperetti, 1990), bubble cloud oscillations (Prosperetti, 1988; Carey and Bradley, 1985; Yoon et al., 1990; Nicholas et al., 1992), and bubble entrapment by capillary waves (Longuet-Higgins, 1993; Kolaini et al., 1993).

Recent laboratory studies of breaking waves were reported by Medwin and Beaky (1989), and by Medwin and Daniel (1990); in these studies, they measured sound generated by gently spilling breakers. This sound consisted of a superposition of damped sinusoidal pressure waves. They concluded that this noise resulted from newly created bubbles oscillating at their linear resonance frequencies. The same conclusion was arrived at by Banner and Cato (1988) where they produced laboratory breaking waves by towing an airfoil in a channel. Laboratory measurements of noise generated by stronger breaking waves have also been made by Kerman (1984), Papanicolaou and Raichlen (1988), Melville et al. (1988), and Loewen and Melville (1991). In all these cases absolute sound-pressure measurements were not obtained because of the reverberation 
of the tanks. For waves of moderate slopes, Loewen and Melville (1991) showed that the acoustic energy radiated by breaking waves was correlated with the mechanical wave energy dissipated during breaking process. Because it is generally assumed that large bubbles are not present in breaking waves, the source of the noise generation below 1 $\mathrm{kHz}$ has been hypothesized by Prosperetti $(1985,1988)$ and Carey (1985) to be due to collective oscillations of bubbles within an individual cloud. Laboratory studies of noise from cylindrical bubble columns by Yoon et al. (1991) and Nicholas et al. (1993) lend credibility to this hypothesis.

Field measurements of noise generation by breaking waves at sea reported by Farmer and Vagle (1988) and by Shonting and Taylor (1988) show a correlation between wind speed and noise intensity. Updegraff (1989) has studied the sound radiated by gently spilling breaking waves in the ocean and concluded that the radiated sound was composed of damped bubble oscillations. Recent laboratory and sea measurements of noise generated by breaking waves suggest that this noise could range as low as several tens of $\mathrm{Hz}$ (McConnel et al., 1992; Chapman, 1991; Kolaini et al., 1991; Kennedy, 1991).

Because of the complexity of the wave-breaking process, it is extremely difficult to clearly identify ambientnoise source mechanisms. After more than a decade of study, it is still unclear to what extent bubble and/or bubble cloud oscillations contribute to sound generation from breaking waves. To understand these source mechanisms, one must first understand the acoustic behavior of a bubble plume, the physical parameters of which can be easily controlled and repeated.

The results reported here involved the generation of a bubble plume by releasing a cylindrical volume of water onto the free surface of a large water tank using containers of various water heights, elevations, and diameters. This was first suggested by Longuet-Higgins at a meeting when the subject of the noise produced by breaking waves was discussed. High-speed cinematography indicated that at higher potential energies of the jet, the "bubble plume" may be a large air-filled "bubble" with a roughened surface that acted as a mixing layer between the air-filled cavity and the host liquid. For simplicity, we will refer to these so called air-field cavities as bubble plumes throughout this report. The acoustic characteristics of the bubble plumes and their relation to the physical parameters of the jet are discussed. The salinity of the water and the roughness of the jets can have significant effects on the production and sound generated from bubble plumes. These effects have also been examined and are discussed.

\section{EXPERIMENTAL PROCEDURES}

The measurements reported here were carried out in a laboratory tank with dimensions of $2.1 \times 2.1 \times 1.8 \mathrm{~m}$ (width, length, and height) by releasing a volume of water onto the free surface of the water tank. The tank was filled with tap water and maintained at ambient temperature $\left(23^{\circ} \mathrm{C}\right)$. Cylindrical containers of various diameters were used to release varying volumes of water. These containers
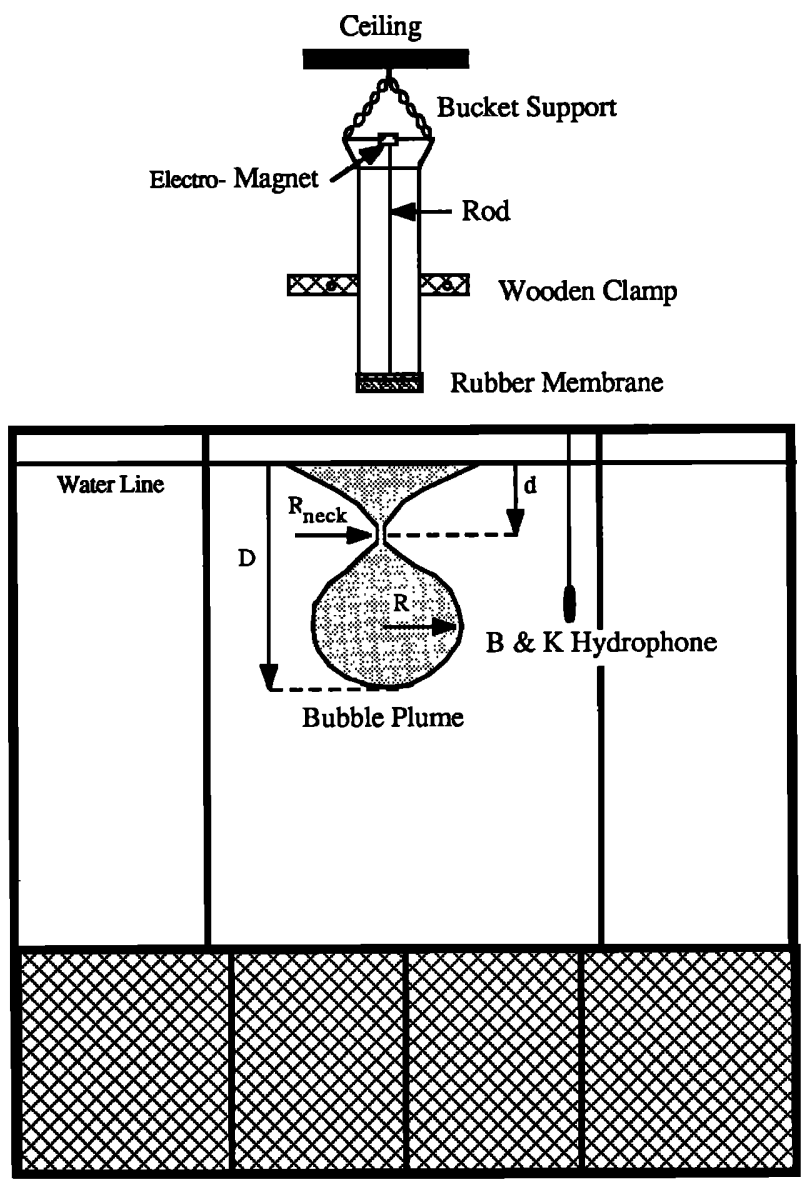

FIG. 1. Schematic drawing of the experimental arrangement (not drawn to scale).

were suspended above the tank and restrained from lateral movement. The water column was supported by a tightly stretched, thin rubber sheet, which was secured to the bottom of the container by a rubber band. The rubber membrane was ruptured by a thin, sharpened rod, which was coaxially suspended inside the container a few inches above the membrane (Fig. 1). Once the membrane was ruptured, the volume of water was transported immediately onto the still-water surface, thus entraining air and generating a cylindrical bubble plume. The air was initially entrained shortly after water impact and continued to be entrained along the jet circumference as the entry progressed. The evolution of the bubble plume in the laboratory tank was recorded with a Kodak Ekta-Pro high-speed video camera operating at 1000 frames per $s$ and rigged with a Nikon 28-mm lens directed perpendicular to the plume axis as viewed through the Plexiglass wall. This process was also recorded with a Photec IV rotating-prism motion picture camera with two lenses operating with speed of 500 frames per s. The sound emission from the plume was measured using a B\&K 8103 broadband hydrophone, which was connected to an HP 5183 digitizing oscilloscope via a B\&K 2635 charge amplifier and was high-pass filtered above 20 $\mathrm{Hz}$ using an analog filter. The digitization speed and conversion gain was $40-\mathrm{k}$ samples/s and 11 bits, respectively. The recorded data were then saved on floppy disks for 
further analysis. The high-speed video images were recorded on VHS video tape for further image processing.

It is important to recognize that we are making measurements in the near field, which means that we are sensitive to both hydrodynamic as well as acoustic pressure fluctuations. Moreover, the tank itself can alter the characteristics of the measured acoustic emissions. We have determined that the frequencies of the interest lie below the cutoff frequency of the enclosure, thus the modal structure of the tank should not significantly alter the shape of the emission spectrum. Nevertheless, the tank serves as a crude approximation to a free field, and in this system we thus cannot make absolute measurements of the radiated acoustic pressure from the plume. We can, however, measure frequency content and consider relative changes in the emissions with respect to changing experimental parameters.

Cylindrical containers with radii ranging from 1.5-9.5 $\mathrm{cm}$ were filled with water heights ranging from $5-45 \mathrm{~cm}$. In addition to changes in the container's radii and water heights, the container elevation from the still-water surface, the container inner-wall roughness, and the salinity of the water were varied.

Figure 2 shows a series of high-speed photographs of bubble plume taken with the Photec IV camera. The portion of the water tank where the water jet enters was also photographed. The plume was brightly lit through the side wall of the tank using studio lights. A 500-W underwater flood light was also located beneath the bubble plume to give extra contrast to the photographs. The thin vertical line on the left-hand side of each frame is a simultaneous image of the acoustic emissions from the plume as measured by a hydrophone and displayed on an analog oscilloscope. The B\&K hydrophone was located about $40 \mathrm{~cm}$ from the plume axis and was submerged about $20 \mathrm{~cm}$ below the still-water surface. This hydrophone holder was clamped to an aluminum I-beam moving across the top of the tank. The analog oscilloscope was set in $x-y$ mode, whereby channel one $(x)$ was receiving the acoustic signal from the B\&K hydrophone and channel two $(y)$ was connected to a function generator that produced a sinusoidal signal with a $1-\mathrm{Hz}$ frequency. By using a sinusoidal signal for the time base, we were able to prevent the temporary disappearance of the acoustic signal from analog oscilloscope's screen which always precedes each sweep when the internal time base was used. The time intervals between the first nine frames, which are sequential but not necessarily consecutive, and shown in Fig. 2 are given in the caption. The rest of the frames are sequential and consecutive with 2-ms intervals.

The total air contained in the detached bubble plumes (see Sec. II) were measured by trapping the plumes under a sliding hood arrangement (Fig. 3). The hood was totally submerged below the water surface and positioned at a depth where only the separated portion of the bubble plume was trapped. This mechanism consisted of a 45 $\times 60 \times 5 \mathrm{~cm}$ (width, length, and height) Plexiglass hood with a slightly curved top which could easily slide on two rails, a quick connect fitting, an electronic delay box to control releasing time, a solenoid-actuated releasing mechanism, and two stiff springs. The front face of the sliding hood was tapered to minimize the disturbance of the surrounding water once set in motion. The hood was held horizontally against spring loadings by a rod connected to the solenoid and away from water jet entrance location. The electronic delay controlled the time interval between the release of the water column and the release of the sliding hood. As soon as the water column was released, the sliding hood was delayed with a pre-specified time and then released. This delay time was adjusted in such a way that the hood trapped the detached bubble plume without distorting it. The delay time could be easily adjusted to suit different experimental conditions. After trapping the bubble plume, time was allowed for rising bubbles to collect under the hood. The quick-disconnect fitting was located in the middle of the hood to which a graduated cylindrical container could be connected. The void fraction was determined by dividing the collected air volume into the total volume of the bubble plume as determined by video and film records. Acoustical measurements of the bubble plume emissions were conducted separately from the air entrainment measurements.

\section{RESULTS}

\section{A. Evolution of the bubble plumes}

The air entrainment process and the resulting acoustic emission generated from a free-falling volume of water is illustrated in Fig. 2. The air was initially entrained shortly after water impact and relatively low-amplitude sound with frequencies around a few $\mathbf{k H z}$ was emitted (frames 1-3). The transient nature of the impact water jet generated a hydrodynamic pressure impulse throughout the receiving fluid and a sudden change of the normal component of velocity at the boundary created a bubbly layer between the jet and the host fluid (frame 4). As the water jet continued to enter the tank the layer grew in length. The rapidly growing bubble plume consisted of a cylinder of water surrounded by the air layer. These images reveal the formation and growth of the cylindrical plume until all the water volume was injected into the tank. As the plume advanced, it formed a "neck" and the water surrounding this neck moved radially inward toward the axis of symmetry (frames 7-11). This process continued until the neck collapsed and a bubble plume separated from the crater region (frame 12). The photographic images show the relatively large-amplitude, low-frequency sound emission which resulted from detachment of the bubble plume. Visual observation suggested that the separated plume was roughly spherical in shape with large void fraction and contained a volume of water located near the center of the bubbly sphere. High-speed cinematography indicated that the "bubble plume" may in reality be a large air-filled "bubble" with a roughened surface that acted as a mixing layer between the air-filled cavity and the host liquid. The detached bubble plume underwent volume pulsations and the radiated acoustic pressure decays with time (frames 12 onward). As the bubble plume oscillated, its size and shape 


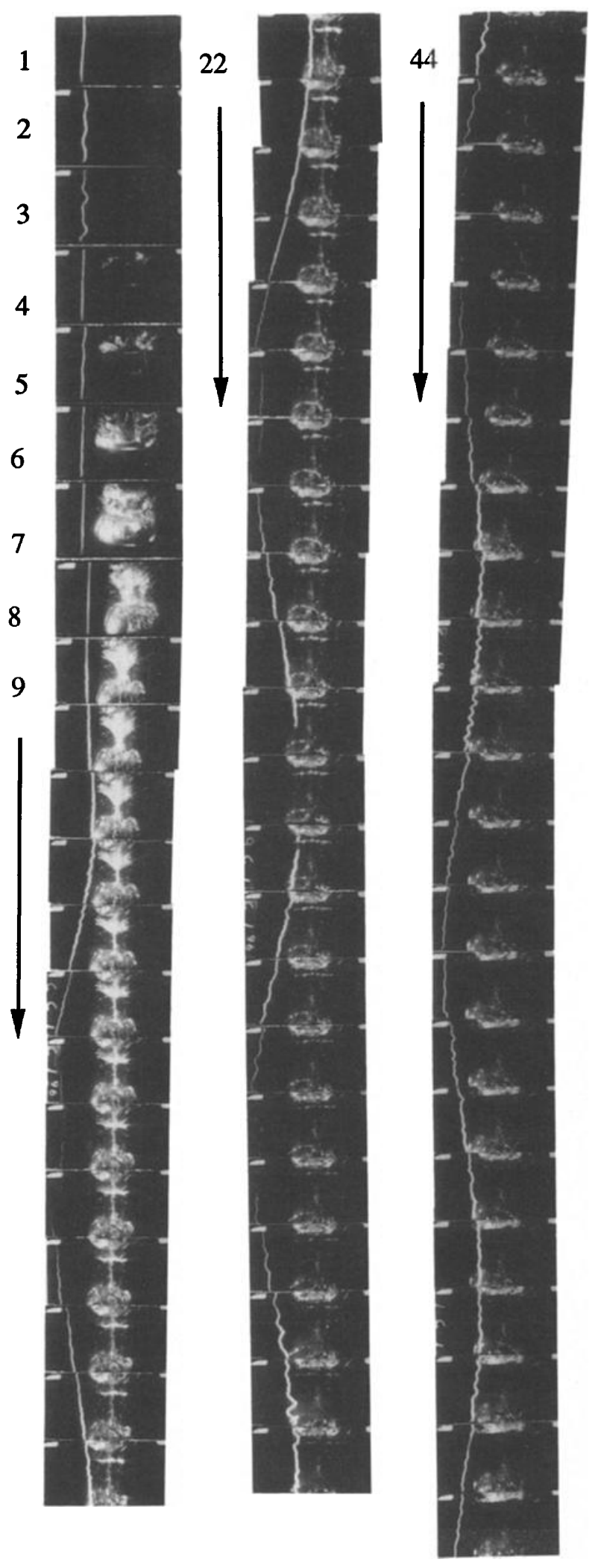

changed and the frequency of oscillation gradually shifted upward. A suggested explanation for this shift in frequency will be given later in this section. After the pulsation subsided, the dispersed bubble cloud rose to the surface. The detached bubble plume shown in Fig. 2 was approximately $11 \mathrm{~cm}$ in radius with a resonance frequency of about $43 \mathrm{~Hz}$. This particular plume was generated by releasing water
FIG. 2. Photographs of a sequence of frames from the high-speed movie depicting the cylindrical plume growth and the spherical plume detachment. The original film was made at a speed of $500 \mathrm{frame} / \mathrm{s}$. The detached bubble plume has a radius of about $11 \mathrm{~cm}$ and fundamental frequency of about $43 \mathrm{~Hz}$. This plume was generated by releasing a cylindrical volume of water with a radius $5.4 \mathrm{~cm}$, a length of $45 \mathrm{~cm}$, and suspended $15 \mathrm{~cm}$ above the still-water surface. The thin line on the left-hand side of the images is an oscilloscope trace showing the radiated acoustic pressure generated by the bubble plume. Frame Nos. 1-9 are successive but not sequential; frames No. 10 to the end are sequential. The large amplitude, low-frequency emissions correlate well with the detachment of spherical bubble plume. This detachment appears to occur near frame No. 11. Time intervals after impact for each frame are as follows: (1) $0 \mathrm{~ms}$, (2) $52 \mathrm{~ms}$, (3) $82 \mathrm{~ms}$, (4) $116 \mathrm{~ms}$, (5) $150 \mathrm{~ms}$, (6) $210 \mathrm{~ms}$, (7) $260 \mathrm{~ms}$, (8) $300 \mathrm{~ms}$, (9) $316 \mathrm{~ms}$, (11-66) each increment $2 \mathrm{~ms}$. from a container with radius of $5.4 \mathrm{~cm}$ and a water height inside the container of $45 \mathrm{~cm}$ that was suspended $15 \mathrm{~cm}$ above the water surface.

The pressure-time traces and corresponding power spectra of bubble plume emissions are shown in Fig. 4(a) and (b). These bubble plumes were generated by releasing varying volumes of water from a cylindrical container with 


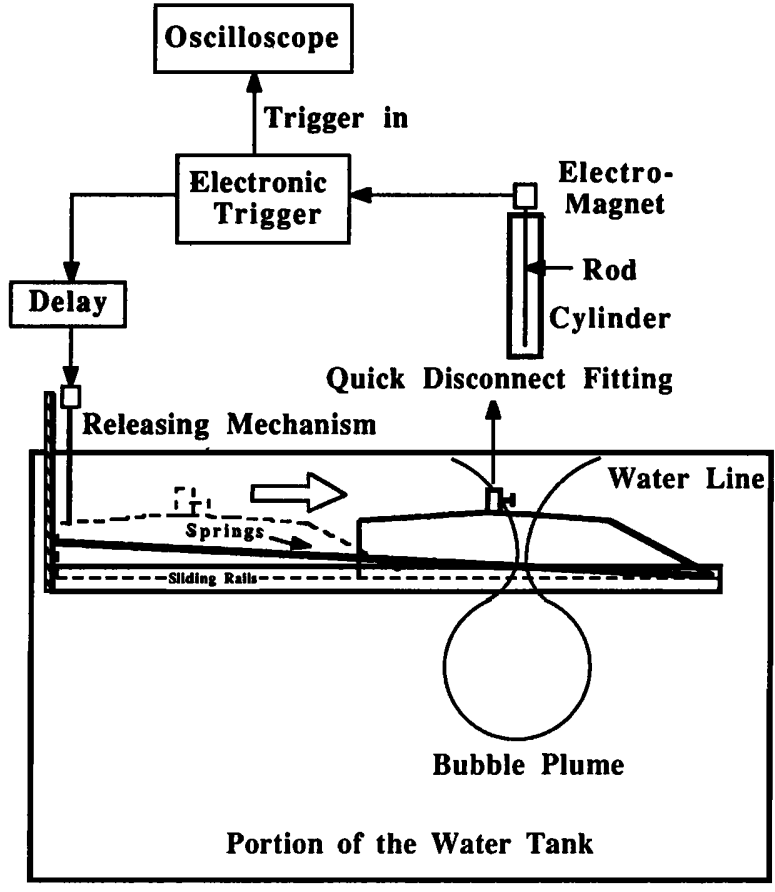

FIG. 3. A schematic drawing of the gas collection apparatus (not to scale). a radius of $5.4 \mathrm{~cm}$, a suspension height of $15 \mathrm{~cm}$ above the still-surface level, and filled with water to heights of 15,25 , 35 , and $45 \mathrm{~cm}$, respectively. The resonance frequencies and accompanying radii of the bubble plumes are: $415 \mathrm{~Hz}, 1.35$ $\mathrm{cm} ; 209 \mathrm{~Hz}, 4.19 \mathrm{~cm} ; 54 \mathrm{~Hz}, 8.53 \mathrm{~cm}$; and $43 \mathrm{~Hz}, 11.21$ $\mathrm{cm}$, respectively. An arbitrary zero-time reference was chosen for these pressure traces. The acoustic emissions by initial water impacts are indicated by (1) in all of the pressure traces shown in Fig. 4(a) and followed by large damped oscillations approximately 59, 188, 255, and 260 ms marked by (2), respectively. The re-entry of the water jet created by the impacts emitted sound that is shown in the first two traces and marked by (3). The power spectra [Fig. 4(b)] indicates a shift to lower frequencies with increasing water volume. The three pronounced peaks (about 1000, 1150, and $1400 \mathrm{~Hz}$ ) that appear in all the plots in Fig. 4(b) and do not shift with water height are probably the tank modes. The visual observations (Fig. 2) as well as pressure traces of Fig. 4(a) suggest that the detached spherical plumes undergo damped volume pulsations which are very much like those of a single spherical bubble detaching from an underwater nozzle. A threedimensional representation of the power spectrum in linear scale versus time and frequency for the pressure trace of Fig. 4 (water height $=45 \mathrm{~cm}$ ) is shown in Fig. 5. This figure demonstrates the low-amplitude acoustic emissions at the early stages of the plume evolution. The relatively large acoustic emissions occur only when the spherical

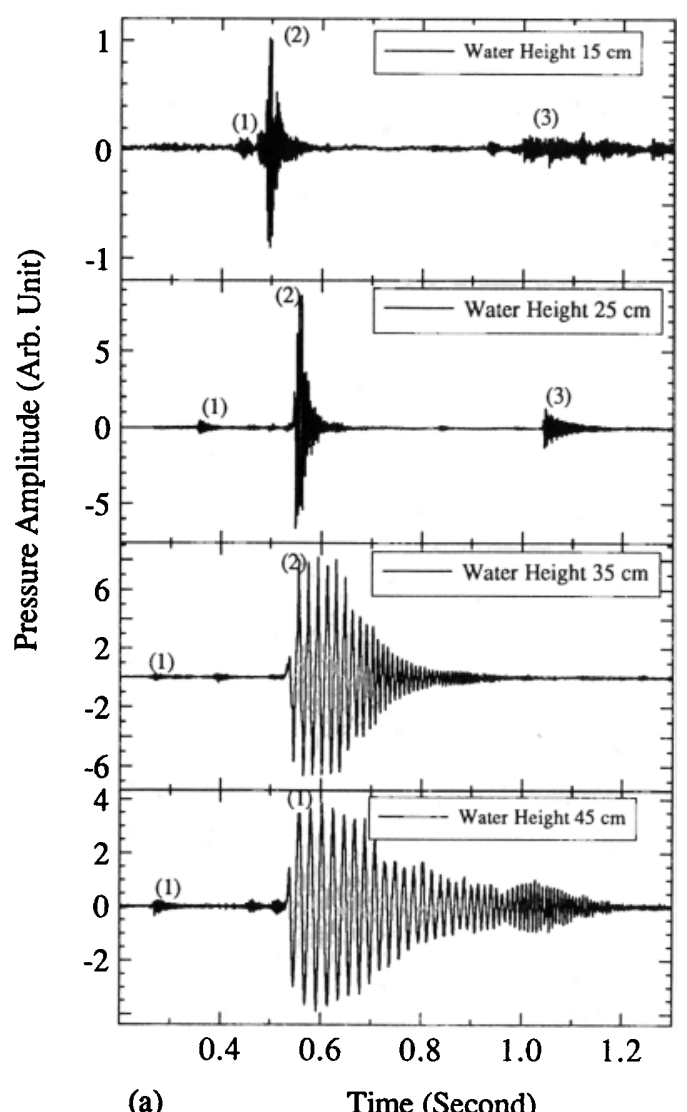

(a)

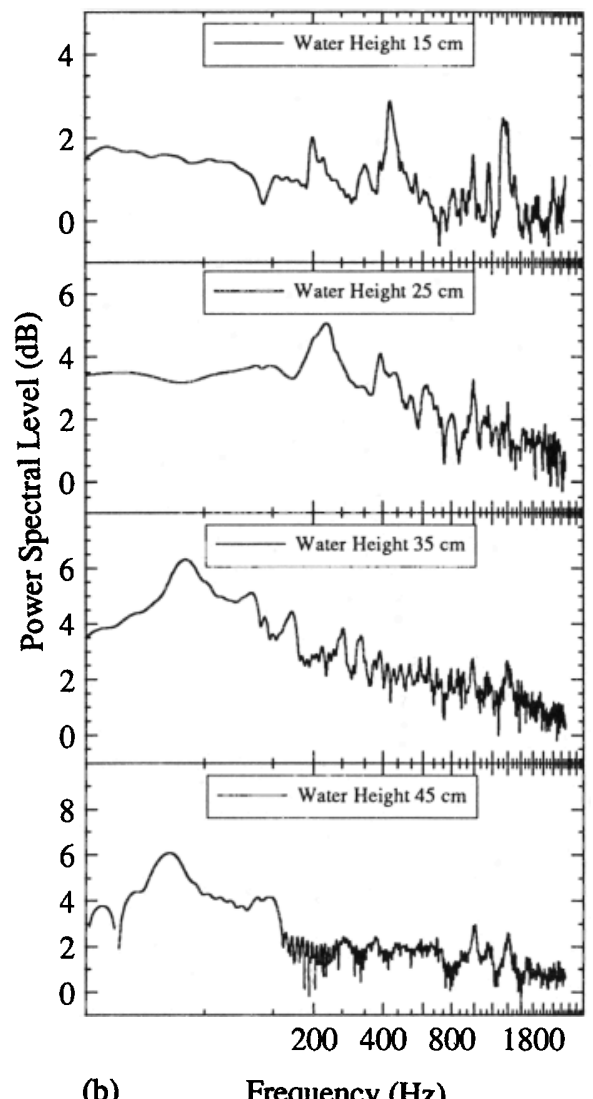

(b)

Frequency $(\mathrm{Hz})$

FIG. 4. Pressure traces and accompanying power spectra of bubble plumes generated by releasing various water heights onto a still-water surface. The cylinder radius was $5.4 \mathrm{~cm}$ with a suspension height of $15 \mathrm{~cm}$. 


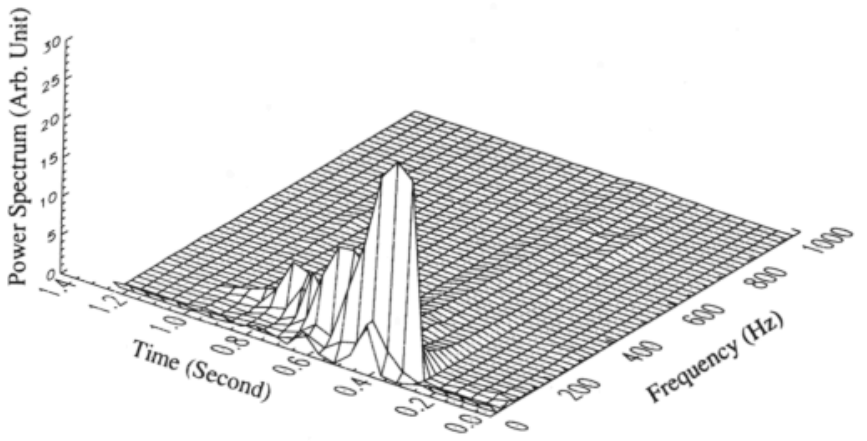

FIG. 5. Three-dimensional representation of the radiated acoustic emissions from a transient jet impact. These data correspond to the bottom traces in Fig. 4. The shift to higher frequencies is evident as the bubble plume evolves.

bubble plume detaches. The shift to higher frequencies with increasing time is also clearly evident from this figure. From sequential photographs of the oscilloscope trace shown in Fig. 2, it is evident that in every instance the dominant low-frequency acoustic emission is correlated with the detachment of the bubble plume.

The radius $R$ of the detached plumes, the crater depth $d$, the neck radius $R_{\text {neck }}$, and the total penetration depth $D$ of bubble plumes were measured from high-speed video images (see Fig. 1). Figure 6 is a plot of the detached plume radius $R$, as a function of the fundamental frequency of the acoustic emissions. Experimental measurements of bubble plumes of various sizes and resonance frequencies are shown in this figure for void fractions $\beta$ ranging from $32 \%-73 \%$. This figure shows that larger plume sizes possess lower resonance frequencies-a trend that would be expected for a single, resonating bubble.

The speed of sound of the collective oscillations of bubble clouds can be modeled by considering the bubbly

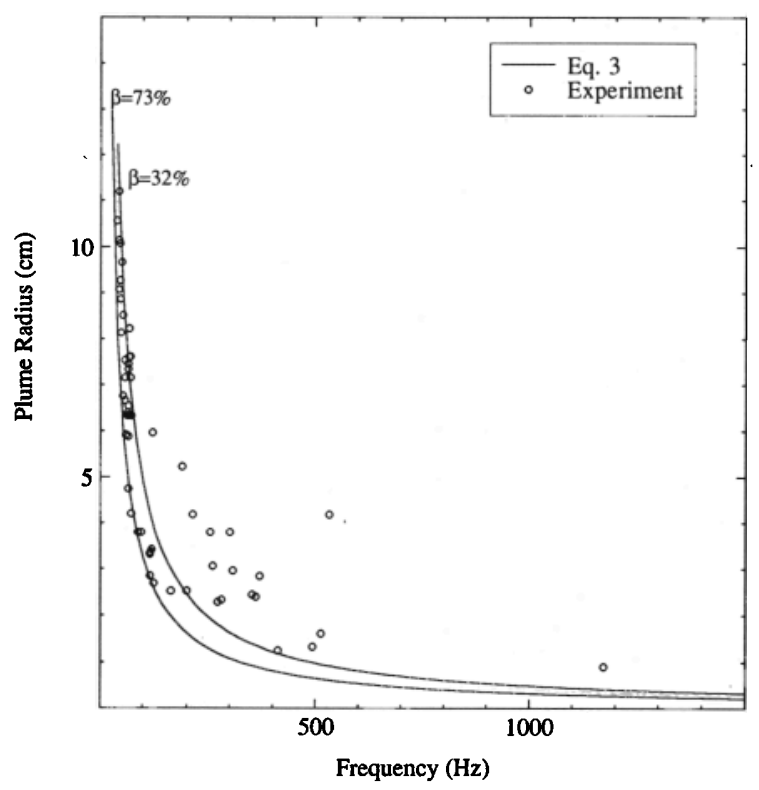

FIG. 6. Bubble plume oscillation frequency as a function of plume radius for a variety of different conditions. The solid lines are the theoretical results given by $\mathrm{Eq}$. (3) for void fractions of $32 \%$ and $73 \%$. region as an "effective" liquid medium of high density ( $\approx$ water) and high compressibility ( $\approx$ air). Theoretical calculations for the model, which have been given by several investigators and most recently given by Carey and Roy (1992), demonstrates a greatly diminished sound speed which remains approximately constant for void fractions $20 \%<\beta<80 \%$. At low frequencies and for isothermal oscillations the sound speed for the mixture is given by,

$$
c_{m} \approx \sqrt{P_{0} / \rho_{0} \beta(1-\beta)},
$$

where $c_{m}$ is the sound speed in the mixture, $P_{0}$ is the ambient pressure, and $\rho_{0}$ is the liquid density. The resonance of the bubble plume occur when

$$
R \approx\left(c_{m} / 2 \pi f\right) \sqrt{3(1-\beta)},
$$

where $R$ is the plume radius and $f$ is the resonance frequency. Substituting Eq. (1) into Eq. (2), a relationship between the bubble plume radius, the resonance frequency, and the void fraction can be obtained:

$$
R \approx(1 / 2 \pi f) \sqrt{3 P_{0} / \rho_{0} \beta} .
$$

The solid lines in Fig. 6 are those obtained from Eq. (3) for constant void fractions of $32 \%$ and $73 \%$. The total void fraction was measured for various bubble plume sizes and these values ranged from $32 \%-73 \%$. There is a good agreement between Eq. (3) and the measured values, especially at lower frequencies. The disparity at higher frequencies probably stems from the fact that these smaller bubble plumes have nonspherical shapes and inexact estimates were made of the equivalent spherical radii. Since these measurements were conducted in two different-sized water tanks, it is seen that the tank-to-tank repeatability of the data is quite good especially for frequencies lower than $200 \mathrm{~Hz}$ (Kolaini et al., 1991).

\section{B. Dependence on initial conditions}

Experimental studies of the dependence of the acoustic emissions on the various physical characteristics of the containers and/or water jets were also performed. A general discussion is presented below for these physical parameters.

\section{Effect of the container radius and water height on acoustic emissions}

The dependence of the plume size and associated acoustic emissions on the height of the water inside the cylindrical containers of various sizes (suspended $15 \mathrm{~cm}$ from the water surface) was measured by changing the water level inside the containers. Figure $7(\mathrm{a})$ is a plot of bubble plume volume as a function of the volume of released water for cylinders with radii 1.64, 3.55, 5.40, and $7.30 \mathrm{~cm}$, respectively. Increasing the water volume increases the plume radius; therefore, the resonance frequency decreases. For a given cylinder radius, there is minimum water volume below which the water jet is unable to generate a bubble plume. The effect of the container radius on the bubble plume detachment was examined by fitting second-order polynomial curves to data shown in Fig. 

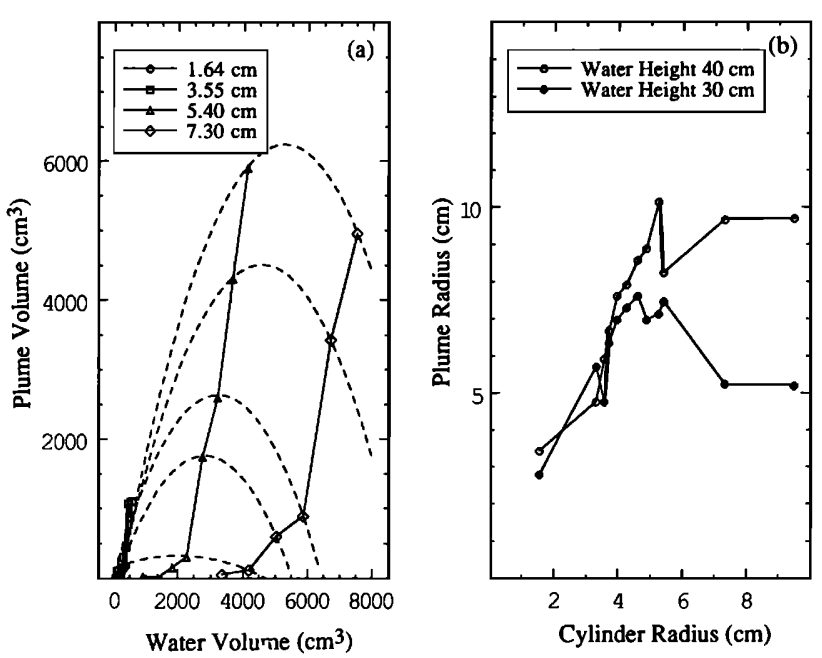

FIG. 7. (a) Variation of the detached plume radius with cylinder water level (water height) for a cylinder radius of $5.4 \mathrm{~cm}$ and a suspension height of $15 \mathrm{~cm}$. The size of the bubble plume depends upon the size of the cylinder and the plume volume increases rapidly with increase in water volume. The dashed lines represent the change in bubble plume radius with cylinder radii for a fixed water height inside the containers. (b) Relationship between plume radii and cylinder radii for two different water heights inside the containers [measurements supporting the dashed lines in part (a)]. The suspension height for this case was $15 \mathrm{~cm}$.

7(a). These curves are shown with dashed lines for various water heights. The polynomial curves suggest that the plume volume increases as square of the container radius and reaches a maximum value depending on the water height in the containers. This effect was also shown in Fig. 7(b) by maintaining the water height constant inside the containers and changing their radii from 1.5 to $9.5 \mathrm{~cm}$ for water heights of 40 and $30 \mathrm{~cm}$. These observations imply that the volume of the entrained gas scales with the crosssectional area rather than the circumference of the jet up to a critical container radius. Above this critical value, measurements show that the total entrained gas and plume radius declines.

\section{Effect of the container height}

Another parameter which could have an important effect on the acoustical characteristics of bubble plumes is the impact velocity of the water jet. Since the slug of water falls freely onto the water surface under the force of gravity alone, the jet velocity can be altered by changing the suspension height of the container. A container size of $5.4 \mathrm{~cm}$ with water height of $45 \mathrm{~cm}$ was suspended above the water surface at elevations ranging from $5-35 \mathrm{~cm}$ and incremented by $5 \mathrm{~cm}$. For each increment, the size of the detached bubble plume and corresponding resonance frequency, void fraction, and pressure were measured. These measurements show that the plume sizes, resonance frequencies, and the void fractions remained reasonably unchanged from one elevation to the other (see Fig. 8). The significant change was found to be the radiated pressure of the detached bubble plume, which increased with increasing jet velocity and the total penetration depth $d$ of the plume. Since other acoustical characteristics of the bubble

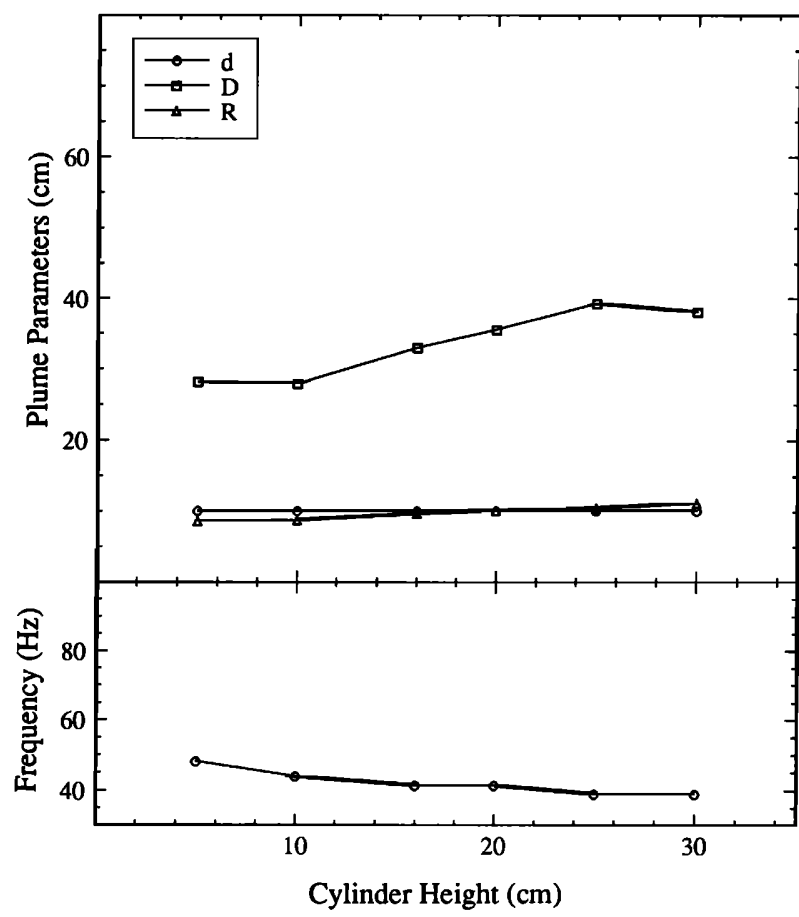

FIG. 8. Dependence of the bubble plume detachment depth $d$, total penetration depth $D$, plume radius $R$, and resonance frequency $f$ on the suspension height of the container. For this case, the radius of the cylinder was $5.4 \mathrm{~cm}$ and it was filled to a height of $45 \mathrm{~cm}$.

plumes remains approximately unchanged relative to change in jet velocity, the relative change in radiated acoustic intensity could be easily calculated. If we assume that the bubble plume, after detachment, radiates energy like a spherical source, the average rate of the energy flux can be computed. For the crude approximation of planetraveling waves, the particle velocity is given by $u=P / \rho_{0} c$, where $P$ is the acoustic pressure with $\rho_{0}$ and $c$ being liquid density and sound velocity, respectively. The average rate of energy flux will thus have a form,

$$
I=\frac{1}{\tau \rho_{0} c} \int_{0}^{\tau} P^{2} d t,
$$

where $\tau$ is the duration of the "event" which was taken to be the same for all the jet velocities. Figure 9 is a plot of the normalized average intensity, as defined in Eq. (4), versus the total potential energy of the water jet, $U=\rho_{0} g V_{\mathrm{w}} H_{\text {ave }}$, where $V_{\mathrm{w}}$ and $H_{\text {ave }}$ are the water volume and average water height from water surface, respectively. The energy flux is normalized by the maximum-measured acoustic intensity. The speed of sound in the liquid is taken to be constant with a value of $1480 \mathrm{~m} / \mathrm{s}$. The linear fit to the measured data suggests that a fixed fraction of the potential energy of the jet was directly converted to acoustical energy. We recognize, however, that a portion of the "acoustic" emissions may in fact be due to near-field hydrodynamics pressure fluctuations. These results should have relevance to ocean studies of the acoustic conversion efficiency of breaking gravity waves. Actually, the use of radiated acoustic energy to monitor gravity wave energy may be more interesting. Unfortunately, the efficiency of conversion from jet poten- 


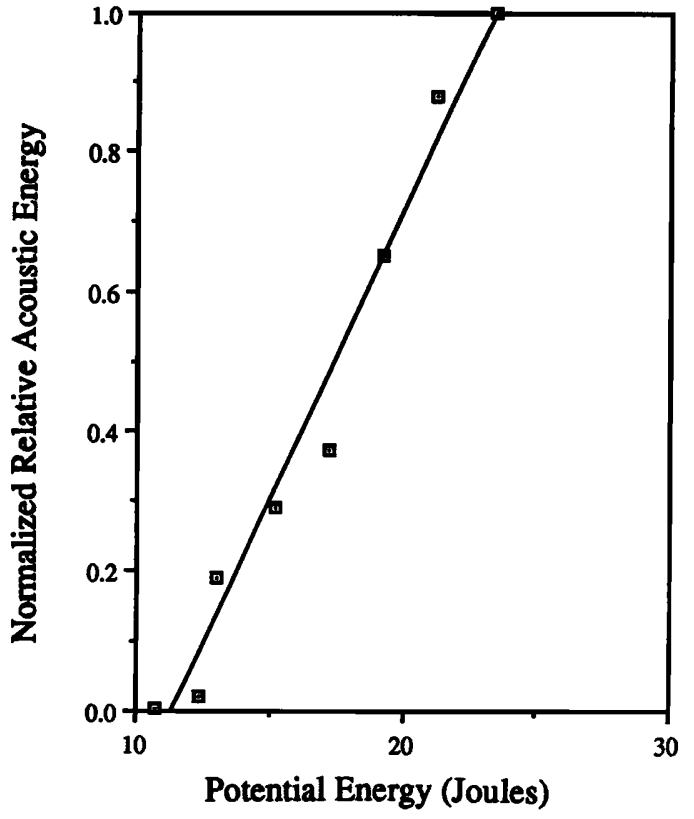

FIG. 9. Variation of the normalized average rate of acoustic energy flux with the gravitational potential energy of the impacting water jet.

tial energy to radiated acoustic energy could not be determined because of the boundaries introduced by the water tank. Results of the laboratory measurements of breaking waves published by Loewen and Melville (1991) suggest that the acoustic energy radiated by breaking waves was approximately proportional to the energy dissipated by breaking waves. Melville and Rapp (1985) have shown in the laboratory that up to $40 \%$ of the total wave energy before breaking can be lost through breaking processes. Data obtained by Loewen and Melville (1991) show that a large fraction of dissipated energy during breaking (30\% to $50 \%$ ) was consumed in entraining the bubble cloud. Results shown in Fig. 9 suggest similar trends as those observed by Melville's group. In order to determine the absolute relationship between the total mechanical energy and the total energy radiated for detached plumes, it is necessary to repeat this experiment in a free field (i.e., a lake or the ocean); such experiments are planned for the immediate future.

\section{Roughness of the container}

In general, when air is entrained into a stationary liquid by a jet, the entrainment rate depends on the roughness of the jet as well as jet's size and velocity (Van de Sande and Smith, 1973). In this study, we have investigated the effect of jet-surface roughness on the production of sound from the detached bubble plume. A cylindrical tube of radius $5.4 \mathrm{~cm}$ was suspended $15 \mathrm{~cm}$ above the host liquid and was roughened by using $1 / 2$-in.-diam hemispherical glass nodules glued to the inside surface of the container. These nodules were glued in a uniform pattern starting at the bottom of the container and extending upward onecontainer diameter. The jet streamlines were monitored outside the tank by high-speed video for both smooth and rough jets. The video images reveal that the smooth con-

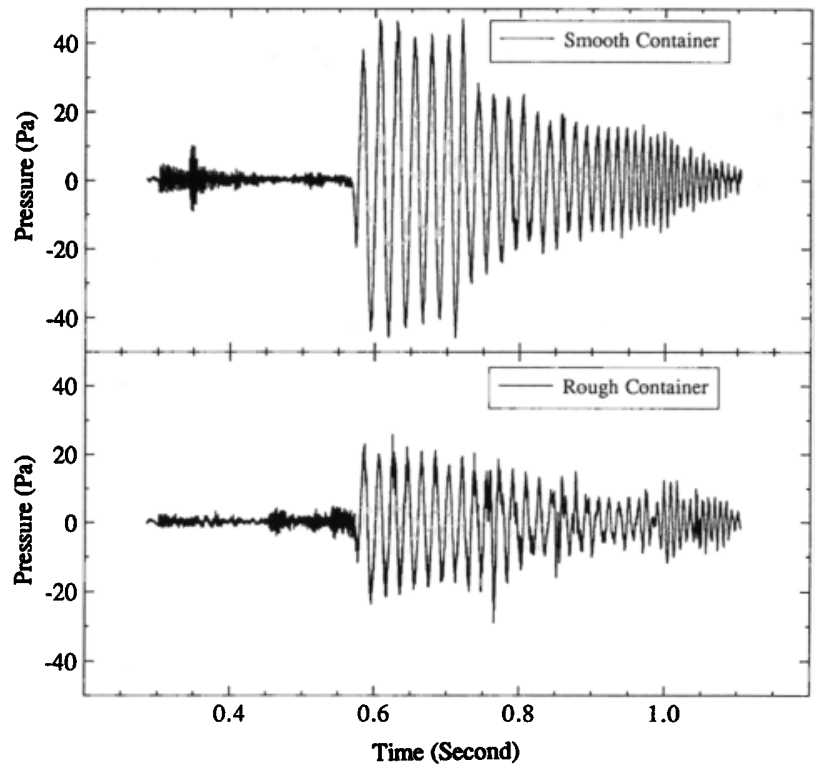

FIG. 10. Acoustic emissions from a bubble plume generated by a container radius of $5.4 \mathrm{~cm}$ filled to a water height of $45 \mathrm{~cm}$ and suspended at a height of $15 \mathrm{~cm}$ with and without cylinder roughness.

tainer produced a laminar flow while the rough container created a turbulent jet. Figure 10 shows pressure traces of the bubble plumes generated by releasing the same volume of water from the same size containers with and without cylinder surface roughness. Measurements show that roughening the jet results in an increase in the resonance frequency $(\sim 20 \%)$ with slight decrease in the size of the plume $(\sim 10 \%)$ and reduction in the total air contained inside the bubble plume $(\sim 30 \%)$. The dependence of the resonance frequency on plume radius still satisfies Eq. (3), provided the void fraction is slightly lower than of the smooth jet $(\sim 10 \%)$. Unlike bubble plumes generated by smooth jets, the presence of a volume of water inside the bubble plume generated by a rough jet was not clear from the video images. These images reveal that bubbles of various sizes were scattered outside the boundary between the bubble plume and the surrounding water. The power spectra of the pressure traces shown in Fig. 10 are plotted in Fig. 11 and the shift to higher frequency of the acoustic emissions of the rough jet is clearly evident. This figure also demonstrates that bubble plumes that are generated by a rough container radiate more energy at higher frequencies (i.e., $f>100 \mathrm{~Hz}$ ) than the smooth ones. The video images showed that the rough jets entrained more air outside the plume boundary, particularly in the crater and the neck regions. In a comparison of the acoustic signals for rough and smooth jets as shown in Fig. 10, it is seen also that there is a reduction of the low-frequency pressure amplitude by more than a factor of two $(\sim 7 \mathrm{~dB})$ for the rough versus the smooth jet. This reduction in pressure amplitude is probably due to the fact that bubbles surrounding the neck of the bubble plume increase the drag on the entrained jet. The source strength (see Sec. II C) as well as acoustic pressure are directly proportional to the particle velocity of the fluid surrounding the neck. Thus a reduc- 


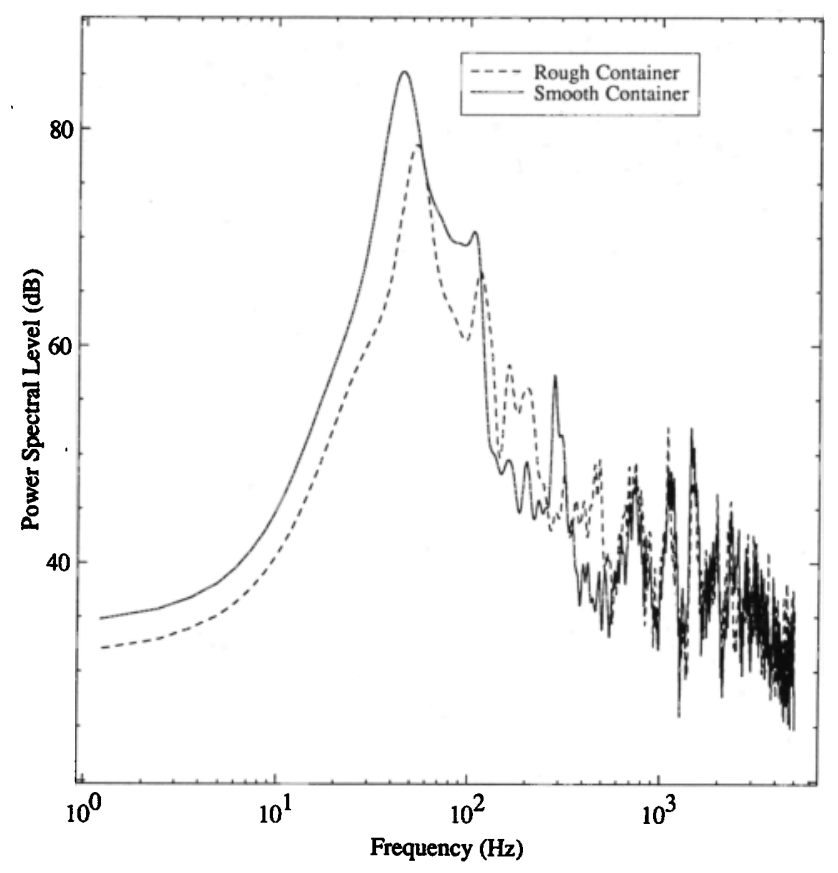

FIG. 11. The power spectral level of the pressure traces shown in Fig. 10.

tion in the fluid particle velocity due to the existence of bubbles outside the neck should reduce the acoustic radiated pressure. Another reason for the reduction in pressure amplitude may be due to the thermal dampening of the isothermal bubble oscillations that can be enhanced at the presence of large number of small bubbles.

\section{Salinity of the fluid}

It is well known that bubbles coalesce much less effectively in the ocean than in fresh water. The ionic properties of salt water apparently prevent coalescence (Pounder, 1986). In order to examine the effect of salinity on bubble plume oscillations, we constructed a $2-\times 2-\times 4$-ft false wall container suspended it in the middle of the larger tank. This container was constructed from milar sheeting, which is both acoustically and optically transparent. Jet impact experiments were then repeated in this smaller tank filled with either fresh or salt water. Enough salt was added to the water to make its salinity comparable with the salinity of the ocean (33-g salt/1000-g water). Figure 12 shows the acoustic emissions and Fig. 13 shows the power spectrum for bubble plumes generated by releasing a volume of water from a 5.4-cm radius container filled with either fresh or salt water to level of $45 \mathrm{~cm}$ and a suspension height of 15 $\mathrm{cm}$. These data show that there are two major differences in acoustic emissions between fresh and salt water. First, it is clear that salinity results in the production of large numbers of small bubbles due to the relative absence of bubble coalescence; this effect is clearly demonstrated by an increase in the power spectra $(\sim 10 \mathrm{~dB})$ in frequencies above $150 \mathrm{~Hz}$ (Fig. 13). Second, a significant decrease in the magnitude of the power spectrum ( $\sim 5-12 \mathrm{~dB})$ at frequencies below $100 \mathrm{~Hz}$ is also clearly shown in Fig. 13. The size of the detached plumes and the radiated fundamental fre-

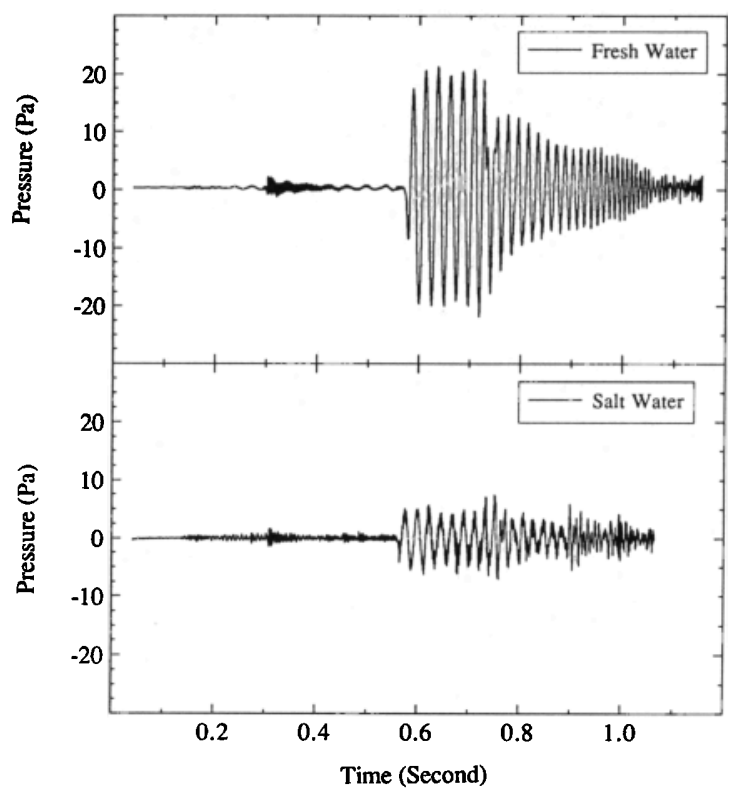

FIG. 12. The pressure traces of a bubble plume generated by a container $5.4 \mathrm{~cm}$ in radius filled to a water height of $45 \mathrm{~cm}$ and suspended to a height of $15 \mathrm{~cm}$, for fresh and salt water. The B\&K hydrophone was located $60 \mathrm{~cm}$ from the plume axis and was submerged $20 \mathrm{~cm}$ below water.

quencies are approximately the same for both cases and the mechanisms for noise generation in these two media are identical. The difference in peak frequency $(\sim 3 \mathrm{~Hz})$ between the salt and fresh water is beyond the resolution sensitivity of our system. The reduction in pressure amplitude is most likely due to the increased number of small bubbles in salt water. This effect may be caused by thermal dampening of the isothermal bubble oscillations, especially at lower frequencies (Prosperetti, 1988).

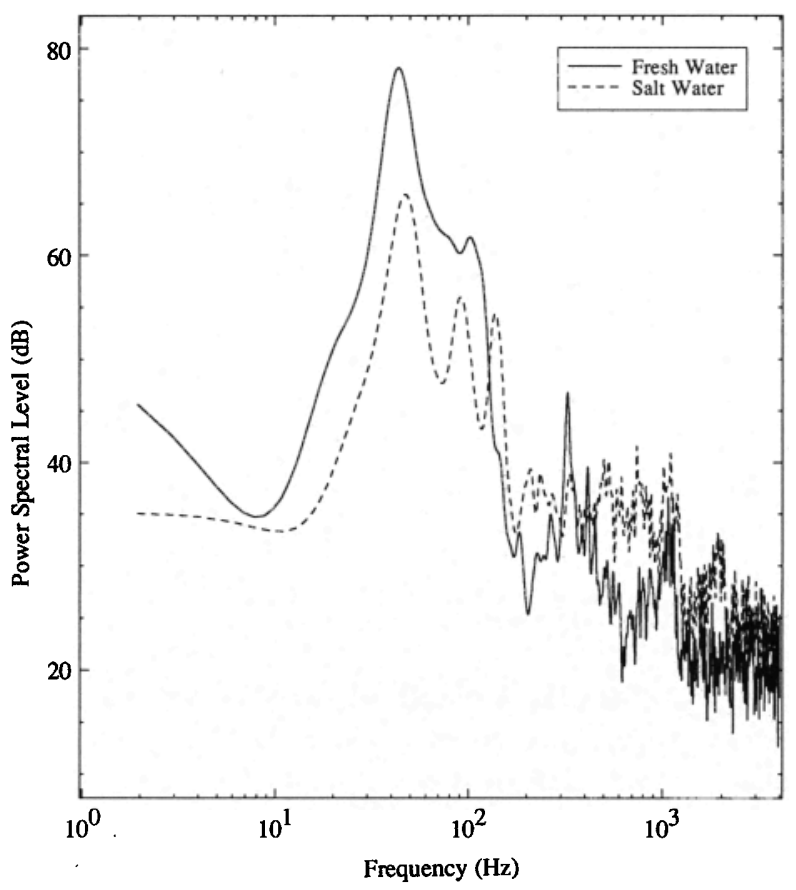

FIG. 13. The power spectral level of the pressure traces shown in Fig. 12. 


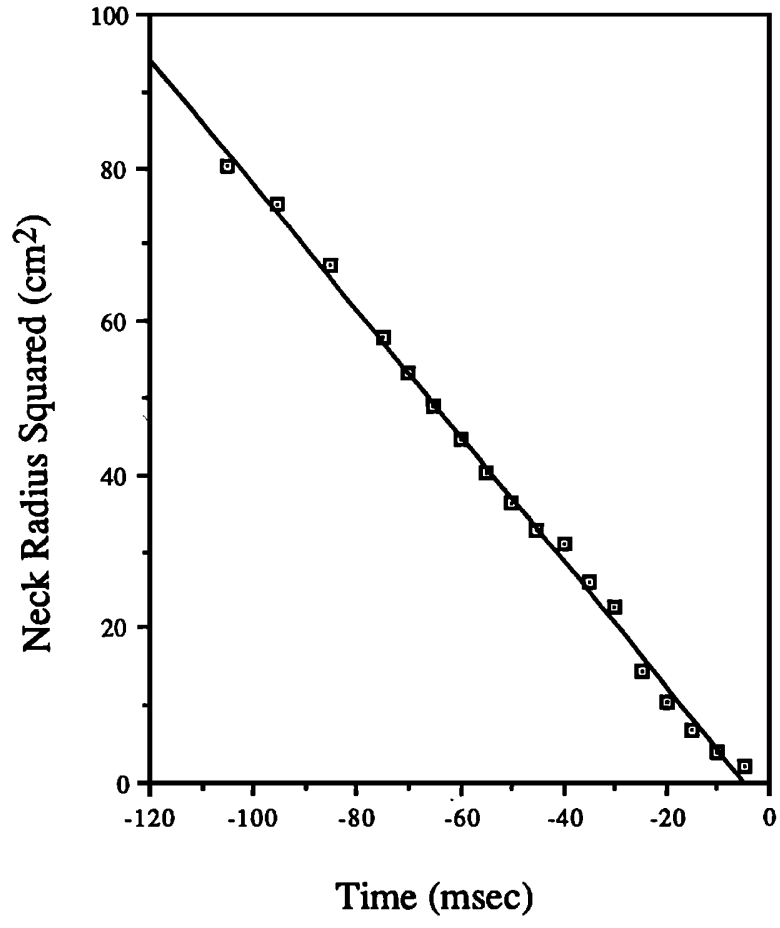

FIG. 14. The square of the size of the plume neck as a function of time for a plume radius of $8.5 \mathrm{~cm}$ and a frequency of $48 \mathrm{~Hz}$.

\section{Physical mechanism for plume oscillation}

It is evident from high-speed images shown in Fig. 2 and the pressure traces shown in Fig. 4(a) that the bubble plume oscillations resemble gas bubble oscillations. Visual observations show that after all of the water has entered the tank, the cylindrical bubble plume forms a "neck" and the water surrounding the neck moves inwards toward the axis of symmetry (frames 7-12, Fig. 2) and forces the plume to separate. The motion of the surrounding water can be described as a continous distribution of sources and sinks along the vertical axis of the plume (LonguetHiggins et al., 1991) that is created by the impacting slug of water. When the bubble plume detaches, there is evidence of a strong axial jet directed downward into the bubble plume and an opposite jet directed upward into the crater formed by the impact; we believe that jet is the physical mechanism that drives the plume into oscillation. This mechanism is similar to the excitation of a single bubble released from an underwater nozzle as described by Longuet-Higgins. Close to the axis of the bubble plume, the radius of the neck $R_{\text {neck }}$ as a function of time can be written as

$$
\frac{d}{d t}\left(\pi R_{\text {neck }}^{2}\right)=-S,
$$

where $S$ denotes the strength of the sink per unit vertical distance. At the instant $t=t_{0}$ where the bubble plume separates, the radius of the neck $R_{\text {neck }}$ behaves like,

$$
R_{\text {neck }} \sim\left(t_{0}-t\right)^{(1 / 2)} \text {. }
$$

Figure 14 shows the square of the radius of the neck as a function of time which is linear, as was predicted by Eq.

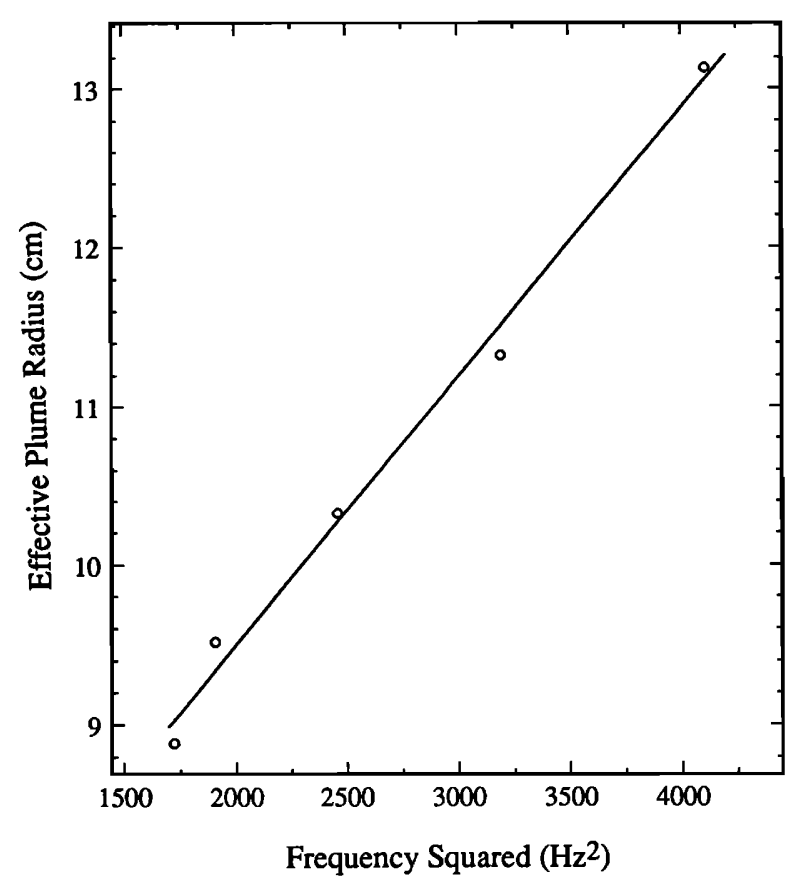

FIG. 15. Variation of the effective plume radius with the square of the radiated acoustic frequency.

(6). This observation supports the contention that inwardflowing water converges along the central axis of the bubble plume. Because of mass continuity, the resulting liquid jets are then required to flow along the vertical axis of the plume.

\section{Shift to higher frequencies}

The spectral content of the acoustic emissions from a bubble plume exhibits a gradual shift to higher frequencies as the pressure decays in time. This effect is easily recognized from the pressure-time traces and from a threedimensional plot [Figs. 4(a) and 5]. Visual observation suggests that the shift to higher frequencies might be due to the increase in size of the plume. After plume detachment, if one assumes that the total volume of air is conserved when entrainment has ceased, then an increase in plume volume in coupled to a decrease in void fraction $\beta$. After detachment, the total volume of air contained in the plume remains constant. Simple dimensional analysis suggests that $\beta$ behaves like,

$$
\beta=V_{\text {air }} / V_{T}=V_{\text {air }} / \frac{4}{3} \pi R^{3} \sim R^{-3} .
$$

Using this equation and Eq. (3) it is clear that the frequency should vary as $f \rightarrow R^{0.5}$. Figure 15 is a plot of the square of the emitted frequency as a function of the effective plume radius. The reasonable fit to a straight line gives strong support to the arguments presented above.

\section{CONCLUSIONS}

In the laboratory, bubble plumes can easily be produced by releasing various volume of water onto a stillwater surface. These bubble plumes, generally spherical in 
shape after detachment, undergo volume pulsations very much like a single bubble detaching from an underwater nozzle. The frequency of oscillation of the detached plume depends on the released water volume, which correlates well with plume sizes and void fractions; it decreases by increasing water volume. The resonance frequency of the bubble plume as a function of plume radius and void fraction satisfy Eq. (3); they extend down to the tens of $\mathrm{Hz}$. The photographic images show a correlation between bubble plume separation and large-amplitude, low-frequency sound emissions. Measurements (Fig. 14) and visual observations suggest that there is an evidence of a strong axial jet directed downward into the bubble plume and an opposite jet directed upward into the crater. This jet appears to be the dominant physical mechanism that drives the plume into oscillations. The resonance frequencies of the detached bubble plumes were examined in two different size tanks and were shown to be repeatable, especially at lower frequencies (Kolaini et al., 1991).

The dependence of the acoustic emissions on the various physical characteristics of the water jets was studied. The detached bubble plume volume increases rapidly with increasing released water volume. For a given size cylinder, there is a minimum water volume below which the water jet is unable to generate a bubble plume. The plume radius increases with the square of the container radius and there exists a critical radius above which the plume radius decreases in size and therefore contains less entrained gas. The effect of the roughness of the jet on the acoustic emissions of bubble plumes were examined by roughening the cylinder. Roughening the jet results in an increase in the resonance frequency, a slight decrease in the size of the plume, and reduction in the total air contained inside the bubble plume. The power spectrum of the rough jet shows the shift to higher frequency of the fundamental mode. The bubble plume generated by rough jets radiate more energy at higher frequencies and less energy at lower frequencies. The reduction in low-frequency power spectrum may be due to the existence of bubbles outside of the neck where the plume separates. The visual observation shows that a lot of smaller bubbles are also present inside the bubble plume, which may explain the increase in power spectrum at higher frequencies. The smaller bubbles may also be the cause of the reduction in the low-frequency spectral levels.

The effects of the salinity of the fluid medium on acoustic emissions are also examined. The salinity results in the production of large numbers of high-frequency bubbles and therefore an increase in the high-frequency power spectrum $(\sim 10 \mathrm{~dB})$. The decrease in the magnitude of the power spectrum at frequencies below $100 \mathrm{~Hz}$ has also been observed. This reduction is probably caused by an increase in the number of small bubbles in salt water which results in enhanced thermal dampening due to isothermal bubble oscillations coupled with an increase in the air/water interfacial area.

A simple explanation can be given for the gradual shift with time to higher frequencies of the radiated noise from the bubble plume. The dimensional analysis suggests that the frequency changes as square root of the plume radius where the air entrainment has ceased and the plume size has increased.

The increase in container elevation (potential energy) does not have a significant effect on plume size, resonance frequency, or void fraction. The only significant change was found to be an increase in the relative radiated acoustic intensity as the potential energy of the cylinder was increased. The correlation between the relative acoustic intensity and potential energy suggests that a fixed fraction of the potential energy of the jet was directly converted to acoustic energy. These results have relevance to ocean studies of the acoustic conversion efficiency of breaking waves. The calculation of the conversion efficiency of the radiated far-field energy of the transient jet was limited because of the boundary effect of the water tank. The laboratory acoustic measurement of breaking waves obtained by Loewen and Melville (1991) show the correlation between the radiated acoustic energy of the bubble cloud generated by breaking waves and the energy dissipated by them. Our results are similar to those of Loewen and Melville.

Experiments have been conducted in a free field where the acoustic conversion efficiency of the transient jets can be calculated. These results will be published in the near future. These laboratory observations, if duplicated in the open sea, may suggest a mechanism for low-frequency emissions from breaking waves (Kennedy, 1991).

\section{ACKNOWLEDGMENTS}

The authors would like to thank Andrea Prosperetti for providing valuable comments and suggestions. This work was supported by the Office of Naval Research.

Banner, M. L., and Cato, D. H. (1988). "Phýsical mechanisms of noise generation by breaking waves-A laboratory study," in Sea Surface Sound: Natural Mechanisms of Surface Generated Noise in the Ocean, edited by B. R. Kerman (Kluwer, Dordrecht, The Netherlands), pp. 429-436.

Carey, W., and Bradley, M. P. (1985). "Low-frequency ocean surface noise sources,” J. Acoust. Soc. Am. Suppl. 1 78, S1.

Carey, W., and Roy, R. A. (1992). "Sound scattering from microbubble distributions near the sea surface," in The Proceedings of the SACLANT Ocean Reverberation Symposium (SCALANT Research Center, La Spezia, Italy).

Chapman, N. R. (1991). "Experimental measurements of acoustic propagation in the ocean," J. Acoust. Soc. Am. 89, 1981 (A).

Crowther, P. A. (1988). "Bubble noise creation mechanisms," in Sea Surface Sounds: Natural Mechanisms of Surface Generated Noise in the Ocean, edited by B. R. Kerman (Kluwer, Dordrecht, The Netherlands), pp. 131-150.

Farmer, D. M., and Vagle, S. (1988). "Observations of high frequency ambient sound generated by wind," in Sea Surface Sound: Natural Mechanisms of Surface Generated Noise in the Ocean, edited by B. R. Kerman (Kluwer, Dordrecht, The Netherlands), pp. 403-415.

Kennedy, R. M. (1991). "Relating ocean acoustic ambient noise to ocean surface dynamics," NUSC Technical Document No. 8879.

Kerman, B. R. (1984). "Underwater sound generation by breaking wind waves," J. Acoust. Soc. Am. 75, 149-165.

Kerman, B. R. (Ed.) (1988). "Natural mechanisms of surface-generated noise in the ocean," in Sea Surface Sound (Kluwer, Dordrecht, The Netherlands), p. 639.

Kerman, B. R. (Ed.) (1993). "Natural mechanisms of surface-generated noise in the ocean," in Natural Physical Sources of Underwater Sound (Kluwer, Dordrecht, The Netherlands). 
Knudsen, V. O., Alford, R. S., and Emling, J. W. (1948). "Underwater ambient noise," J. Mar. Res. 7, 410-429.

Kolaini, A., Roy, R. A., and Crum, L. A. (1993). "The production of high-frequency ambient noise by capillary wave," in Natural Physical Sources of Underwater Sound, edited by B. Kerman (Kluwer, Dordrecht, The Netherlands).

Kolaini, A., Roy, R. A., and Crum, L. A. (1991). "An investigation of the acoustic emissions from a bubble plume," J. Acoust. Soc. Am. 89, 2452-2455.

Loewen, M. R., and Melville, W. K. (1991). "Microwave backscatter and acoustic radiation from breaking waves,” J. Fluid Mech. 224, 601-623.

Longuet-Higgins, M. S. (1989). "Monopole emission of sound by asymmetric bubble oscillations," J. Fluid Mech. 201, 525-565.

Longuet-Higgins, M. S. (1990a). "Bubble noise spectra," J. Acoust. Soc. Am. 87, 652-661

Longuet-Higgins, M. S. (1990b). "An analytical model of sound production by rain-drops," J. Fluid Mech. 214, 395-410.

Longuet-Higgins, M. S. (1993). "Bubble noise mechanisms-A review," in Natural Physical Sources of Underwater Sound, edited by B. Kerman (Kluwer, Dordrecht, The Netherlands).

Longuet-Higgins, M. S., Kerman, B. R., and Lunde K. (1991). "The release of air bubble from an underwater nozzle," J. Fluid Mech. 230, 365-390.

McConnel, S. O., Schilt, M. P., and Dworski, J. G. (1992). "Ambient noise measurements from $100 \mathrm{~Hz}$ to $80 \mathrm{kHz}$ in an Alaskan Fjord," J. Acoust. Soc. Am. 91, 1990-2003.

Medwin, H., and Beaky, M. M. (1989). "Bubble sources of the Knudsen sea noise spectra," J. Acoust. Soc. Am. 86, 1124-1130.

Medwin, H., and Daniel, A. C. (1990). "Acoustical measurements of bubble production by spilling breakers," J. Acoust. Soc. Am. 88, 408412.

Melville, W. K., and Rapp, R. J. (1985). "Momentum flux in breaking waves," Nature 317, 514-516.

Melville, W. K., Loewen, M. R., Felizardo, F. C., Jessup, A. T., and Buckingham, M. J. (1988). "Acoustic and microwave signatures of breaking waves," Nature 336, 54-59.

Nicholas, M., Oguz, H. N., Prosperetti, A., Roy, R. A., and Crum, L. A., "Normal modes and excitation of a bubble column," J. Acoust. Soc. Am. (submitted).

Ogüz, H. N., and Prosperetti, A. (1990). "The underwater noise of rain," J. Fluid Mech. 228, 417-442.
Papanicolaou, P., and Raichlen, F. (1988). "Wave and bubble characteristics in the surf zone," in Sea Surface Sound (Kluwer, Dordrecht, The Netherlands), pp. 94-109.

Pounder, C. V. (1986). "Sodium chloride and water temperature effects on bubbles," in Oceanic Whitecaps, edited by E. C. Monahan and G. MacNiocaill (Reidel, Hingham, MA), p. 278.

Prosperetti, A. (1985). "Bubble-related ambient noise in the ocean," J. Acoust. Soc. Am. Suppl. 1 78, S2.

Prosperetti, A. (1988). "Bubble-related ambient noise in the ocean," J. Acoust. Soc. Am. 84, 1042-1054.

Prosperetti, A. (1988). "Bubble dynamics in oceanic ambient noise," in Sea Surface Sounds: Natural Mechanisms of Surface Generated Noise in the Ocean, edited by B. R. Kerman (Kluwer, Dordrecht, The Netherlands), pp. 151-1171.

Prosperetti, A., Pumpherey, H. C., and Crum, L. A. (1989). "The underwater noise of rain," J. Geophys. Rev. 94, 3255-3259.

Pumphrey, H. C., Crum, L. A., and Bjørnø, L. (1989). "Underwater sound produced by individual drop impacts and rainfall," J. Acoust. Soc. Am. 85, 1518-1526.

Pumphrey, H. C., and Crum, L. A. (1990). "Free oscillations of nearsurface bubbles as a source of the underwater noise of rain," J. Acoust. Soc. Am. 87, 142-148.

Scrimger, J. A. (1985). "Underwater noise caused by precipitation," Nature 318, 647-649.

Scrimger, J. A., Evans, D. J., and Yee, W. (1989). "Underwater noise due to rain-Open ocean measurements," J. Acoust. Soc. Am. 85, 726 731.

Shonting, D., and Taylor, N. (1988). "On the spectra of wind generated sound in the ocean," in Sea Surface Sounds: Natural Mechanisms of Surface Generated Noise in the Ocean, edited by B. R. Kerman (Kluwer, Dordrecht, The Netherlands), pp. 417-427.

Updegraff, G. E. (1989). "In situ investigation of sea surface noise from a depth of one meter," Ph.D. thesis, University of California, San Diego.

Van de Sande, E., and Smith, J. M. (1973). "Surface entrainment of air by high velocity water jets," Chem. Eng. Sci. 28, 1161-1168.

Wenz, G. M. (1962). "Acoustic ambient noise in the ocean: Spectra and sources," J. Acoust. Soc. Am. 34, 1936-1956.

Yoon, S. W., Crum, L. A., Prosperetti, A., and Lu, N. Q. (1989). "An experimental investigation of bubble clouds as sources of ambient noise," J. Acoust. Soc. Am. 89, 700-706. 